upon the application of the definition laid down by the Homicide Act 1959, in practice juries may be more influenced by various intangibles, such as their emotional reactions to the circumstances, the skill and persuasiveness of defence and prosecution counsel, the attitudes of the Judge presiding etc. The final question is whether or not this process is a 'just' one. I have my doubts. I would be interested to hear the views of other forensic psychiatrists.

Chris Green

AMI Stockton Hall Hospital

Stockton-on-the-Forest

York YO3 9UN

\section{The use of old and new antidepressants}

DeAr Sirs

At a recent conference on the economic evaluation of antidepressant drugs, virtually all the speakers felt that the new antidepressants, being safer in overdose, should be prescribed in preference to the older tricyclic drugs which should no longer be considered a first line treatment for depression. One speaker highlighted the number of litigation cases in the United States against psychiatrists whose patients had committed suicide using these drugs.

What is being said? Is it now negligence to prescribe amitryptiline instead of say, lofepramine or fluoxetine? The professor of psychopharmacology believed that the new antidepressants were a safer alternative. The poisons expert said that there were almost $\mathbf{4 0 0}$ deaths per year associated with tricyclic overdosage and only a very small number associated with the newer antidepressants. The senior lecturer replied that there was overwhelming evidence that the new antidepressants were as efficacious as tricyclics and also safer. Only the professor of general practice disagreed and said there were many situations in which a sedative tricyclic would be his first choice.

The professor of psychiatry stated that it was for the courts to decide negligence. But, as opinion leaders, all the above speakers carry tremendous weight as it is they who are called as expert witnesses and their views will shape the law. I am happy to prescribe the new antidepressants but there are situations in which I would prescribe a tricyclic in preference. To imply negligence because one writes such a prescription is a very serious issue.

The grounds for concern over the tricyclic related deaths per million prescriptions seem vastly oversimplified. Who are these patients? What is their diagnosis? How careful was the prescription? Was a proper assessment of suicide risk made? Do patients who fail to kill themselves by taking an overdose of a new antidepressant go onto kill themselves by another method?
I would suggest it is time for the College to produce a consensus statement on the indications for the use of old and new antidepressants. It is too important an issue to be left to the courts to decide. Depression is our bread and butter and I for one do not wish to be that meat in the sandwich.

Richard CAPLAN

The Peter Hodgkinson Centre

County Hospital

Lincoln LN2 SQY

\section{Community homes run by untrained staff}

DeAr Sirs

Increasing numbers of people suffering from chronic mental illness live in staffed private homes, often in seaside towns, run either for profit or by voluntary organisations. These homes are registered under the Residential Homes Act (1984), some of which have received criticism.

The failure of this legislation to address the standards of care has been often stated (National Institute for Social Work, 1988). The scandals of abuse and neglect in homes for the elderly and the ineffectiveness of the statutory supervision have been reported by the media.

An extraordinary home, where adults suffering from schizophrenia wore nappies, were fed baby bottles by the staff and stood in the corner when 'naughty' was the subject of a Radio 4 documentary (Face the Facts, 10 February 1992). Professor Leff stated that this environment was likely to provoke acute relapses in those residents suffering from schizophrenia.

Dr Graham Thornicroft and I recently surveyed a sample of staffed homes registered for the under $65 \mathrm{~s}$, in Southend-on-Sea (submitted for publication) and found them to be of a good physical standard. It was my impression that the staff in the homes were well motivated to care for their residents. However, care homes where none of the staff had had previous psychiatric nursing experience tended to allow their residents less autonomy than homes run by carers with psychiatric nursing qualifications. Environments where residents are allowed comparatively little autonomy, may tend to worsen patients' disabilities and were present in some hospitals 30 years ago (Wing \& Brown, 1970). I would contend that since appropriate training has not been offered to lay carers in privately run staffed homes by the local psychiatric services, they have not assimilated the positive changes of psychiatric in-patient care, which over the last 30 years have led to increasingly less restrictive ward environments (Curson et al, 1991).

It is ironic that in the rush towards deinstitutionalisation, the impoverished social environments of 